\title{
Reactive Zinc Extraction in MRDC Column; Case Study by Mathematical Modelling and Applying the Droplet Size Distribution with Forward Mixing Approach
}

\section{Benyamin Shakib}

Sharif University of Technology

\section{Rezvan Torkaman}

Nuclear Science and Technology Research Institute

Meisam Torab-Mostaedi

Nuclear Science and Technology Research Institute

Mojtaba Saremi

Amirkabir University of Technology

Mehdi Asadollahzadeh ( $\nabla$ mehdiasadollahzadeh@iust.ac.ir)

Nuclear Science and Technology Research Institute

\section{Research Article}

Keywords: Zinc Extraction, MRDC Column, Mass Transfer Performance, Chemical Reaction System, Forward Mixing Model

Posted Date: July 7th, 2021

DOl: https://doi.org/10.21203/rs.3.rs-668189/v1

License: (c) (i) This work is licensed under a Creative Commons Attribution 4.0 International License.

Read Full License 


\title{
Reactive Zinc Extraction in MRDC Column; Case Study by Mathematical Modelling and Applying the Droplet Size Distribution with Forward Mixing Approach
}

\author{
Benyamin Shakib ${ }^{\mathrm{a}}$, Rezvan Torkaman ${ }^{\mathrm{b}}$, Meisam Torab-Mostaedi ${ }^{\mathrm{b}}$, Mojtaba Saremi ${ }^{\mathrm{c}}$, Mehdi \\ Asadollahzadeh $^{\mathrm{b}}$
}

${ }^{a}$ Department of Energy Engineering, Sharif University of Technology, P.O. Box 11365-8639, Tehran, Iran

${ }^{\mathrm{b}}$ Nuclear Fuel Cycle Research School, Nuclear Science and Technology Research Institute, P.O.

Box: 11365-8486, Tehran, Iran

${ }^{\mathrm{c}}$ Energy Engineering and Physics Department, Amirkabir University of Technology, P.O. Box:

$$
\text { 15875-4413, Tehran, Iran }
$$

Corresponding author: M. Asadollahzadeh (masadollahzadeh@aeoi.org.ir; mehdiasadollahzadeh@iust.ac.ir; mehdiasadollahzadeh@yahoo.com) Tel: +982188221117; Fax:+982188221116 


\begin{abstract}
In this survey, the reactive mass transfer data are determined for zinc extraction from chloride solution using $\mathrm{D}_{2}$ EHPA in the MRDC extraction column. The numerical analysis for evaluating the column performance is applied to describe mass balance equations. Four mathematical models (backflow, forward mixing, plug flow, and axial dispersion) are investigated to compute the mass transfer coefficients of the dispersed phase. The solvent extraction experiments showed that the optimum zinc transport efficiency in rotor speed of $410 \mathrm{rpm}$ in this column is equal to 98.85\% and 99.85 for extraction and stripping stages, respectively. The model's achievement is compared with the solvent extraction data and a significant validity is obtained by coupling the forward mixing approach. The mathematical modeling expresses that the coefficients of axial dispersion and backflow based on the continuous phase increase by an increase in the rotor speed and inlet continuous phase rate. While these coefficients reduce at a higher inlet dispersed phase rate. The FMM method is preferred to predict the reactive mass transfer rate in the MRDC column due to the lowest relative deviation. The experimental study and mathematical modeling in this report provide beneficial information about the metallurgical industry to design solvent extraction equipment.
\end{abstract}

Keywords: Zinc Extraction, MRDC Column, Mass Transfer Performance, Chemical Reaction System, Forward Mixing Model 


\section{Introduction}

Zinc extraction from the industrial residue is substantial because of usages in electrical equipment and the chemical industries such as cosmetics, rubber, pharmaceuticals, and batteries 1,2. Therefore, different methods have been investigated for the recovery of zinc ions from effluents, such as solvent extraction ${ }^{3}$, ion exchange ${ }^{4}$, and precipitation ${ }^{5}$. The several benefits especially less expensive setup, more product purity, and wide selectivity are the features of the solvent extraction method ${ }^{6}$. In recent decades, different acidic extractants such as $\mathrm{D}_{2} \mathrm{EHPA}^{7}$, PC-88A ${ }^{8}$, Cyanex $272^{9}$, Cyanex $302^{10}$, and Cyanex $921^{11}$ have been commonly suggested for $\mathrm{Zn}$ (II) extraction from sulfate medium. The selective extraction of zinc from manganese and cadmium in the hydrochloric acid media using $\mathrm{D}_{2}$ EHPA has been investigated by Jafari and coworkers ${ }^{12}$. By considering the impact of contact time, equilibrium $\mathrm{pH}$, extractant concentration, $\mathrm{O} / \mathrm{A}$ ratio, and temperature on the solvent extraction process, they investigated the required theoretical stages for zinc extraction as well as the thermodynamic behavior of chemical reaction. Keshavarz Alamdari and co-workers studied the separation of zinc and cadmium from the synthetic sulfate leach solution by the synergistic effect of MEHPA and $\mathrm{D}_{2}$ EHPA ${ }^{13}$. The experimental work on the zinc extraction from hydrochloric acid solution by coupling the effects of Cyanex 272 and N1923 was reported by Jia and co-workers, which compared with the zinc (II) extraction, the insignificant impact of synergism solvent extraction on the cadmium (II) was

observed ${ }^{14}$. A.M.I. Ali and co-workers performed the solvent extraction experiments for extracting the zinc ions with the Cyanex 272 in the mixer-settler unit ${ }^{15}$. The feasibility of the proposed flow sheet for the elimination of zinc from industrial waste solutions was also conducted in a 15 stage-horizontal mixer-settler unit. 
Several mass transfer devices have been developed to perform solvent extraction tests ${ }^{16}$. The amount of turbulence in the liquid-liquid systems and the interfacial area is directly proportional by enhancing the efficiency of the reactive extraction rate ${ }^{17}$. Mechanically rotating columns are extremely applied in the hydrometallurgy, pharmacy, and nuclear industry. Among various types of these columns, the RDC column achieves acceptable extraction efficiency because of its high throughput. The MRDC column with the perforated configuration is one of the upgraded versions of the RDC column, which improves the distribution of the droplets and mass transfer performance ${ }^{18,19}$.

The column internal diameter and the total height of the extractor are the main parameters in order to evaluate, design, and scale up the extraction columns. Hydrodynamic characteristics comprising droplets behavior, holdup of the dispersed phase, slip velocity, characteristic velocity, and flooding points are vital to determine the column internal diameter ${ }^{20,} 21$. Knowledge of mass transfer evaluation is of essential significance for obtaining the column height, and theoretical models are used for calculating this function ${ }^{22}$. In recent years, the complication and importance of mass transfer rate were led to conduct several studies on mass transfer performance in the RDC columns ${ }^{23-26}$. The experimental and numerical studies on the evaluation of mass transfer data in the RDC columns centralizes on the physical systems, and simplified equations were utilized for interpreting the column performance without consideration of the chemical resistance to mass transfer ${ }^{27-29}$. The published correlations were also compared with the experimental results for investigating the mass transfer rate, which these investigations are still far from satisfactory to describe the reactive and non-reactive systems ${ }^{30,31}$.

Optimum situations and used operating parameters determination is established to design the solvent extraction process by evaluating the concentration profile curves. The relation of overall 
mass transfer rates with the physical properties and operational variables can be calculated by applying the theoretical models such as plug flow, forward mixing, backflow, and axial diffusion 32, ${ }^{33}$. As a result, creating theoretical models can be acknowledged as one of the foremost influential and time-saving methodologies for assessing column performance.

Literature survey indicates that the PFM approach is used to compute the mass transfer predictions in the mixer-settlers units by assuming the ideal plug flow ${ }^{34}$. The non-uniformity of drops along the extraction column leads to deflection from the ideal conditions in which this phenomenon causes remarkable errors in the calculation steps. For this reason, the modified plug flow model is presented as backflow and axial dispersion models in terms of non-ideal state. The axial mixing coefficients based on the dispersed phase and continuous phase $\left(\mathrm{E}_{\mathrm{d}}\right.$ and $\left.\mathrm{E}_{\mathrm{c}}\right)$ are used at the axial dispersion model to convert some deviation in the plug flow model to high efficiency. When the active height of the mass transfer device divides by the tiny lengths in terms of the specific volumetric parts, the backflow mathematical model can be applied for predicting the reactive mass transfer rate. The backflow from the present stage to the prior stage is formulated by axial mixing in the mentioned model, which represented as $\alpha$ and $\beta$ for continuous and dispersed phases, respectively. In order to approach the actual extraction conditions, the drop behavior and terminal velocity of dispersed phase droplets are considered in the forward mixing model, and consequently, the forward mixing model (FMM) is better than the other mentioned models.

Several investigations on the MRDC column with the perforated structure have been reported under physical systems in the literature ${ }^{35-37}$. But, scanty investigations have been observed for chemical reaction conditions in the mentioned column ${ }^{30,38}$. However, for the first time, the solvent extraction technique has been utilized to remove zinc ions from the chloride leach 
solution in the MRDC column. The mathematical modeling study in this extractor to evaluate the mass transfer performance is the new findings and novelty of this research in the field of heavy metals extraction. The analysis of reactive mass transfer rate based on the dispersed phase is developed by associating four theoretical mass transfer models and hydrodynamic parameters for zinc transport in the extraction and stripping stages.

\section{Mathematical modeling for mass transfer coefficients}

Four usual models for studying mass transfer in the liquid-liquid extraction columns are plug flow model (PFM), axial dispersion model (ADM), back flow model (BFM) and forward mixing model (FMM), which are illustrated in the following.

Note: In all models, equations and boundary conditions are derived for mass transfer state from the continuous to dispersed phase.

\subsection{Plug Flow Model (PFM)}

$\frac{d X}{d Z}+\Omega N T U_{o d}(X-Y)=0$

$\frac{d Y}{d Z}+N T U_{o d}(X-Y)=0$

Boundary conditions:

$Z=0 \rightarrow X^{0}=X^{i n}=1$

$Z=1 \rightarrow Y^{1}=Y^{i n}=0$

\subsection{Back Flow Model (BFM)}

$(1+\alpha) X_{n-1}-(1+2 \alpha) X_{n}+\alpha X_{n+1}-\frac{\Omega N T U_{o d}}{N}\left(X_{n}-Y_{n}\right)=0$

$(1+\beta) Y_{n+1}-(1+2 \beta) Y_{n}+\beta Y_{n-1}+\frac{N T U_{o d}}{N}\left(X_{n}-Y_{n}\right)=0$

Boundary conditions: 
$Z=0 \rightarrow\left\{\begin{array}{l}X_{0}+\alpha\left(X_{0}-X_{1}\right)=1 \\ Y^{0}=Y_{0}=Y_{1}\end{array}\right.$

$Z=1 \rightarrow\left\{\begin{array}{l}X^{N+1}=X_{N+1}=X_{N} \\ Y_{N+1}-\beta\left(Y_{N}-Y_{N+1}\right)=0\end{array}\right.$

\subsection{Axial Dispersion Model (ADM)}

$\frac{d X}{d Z}-\frac{1}{P e_{c}} \frac{d^{2} X}{d Z^{2}}+\Omega N T U_{o d}(X-Y)=0$

$\frac{d Y}{d Z}+\frac{1}{P e_{d}} \frac{d^{2} Y}{d Z^{2}}+N T U_{o d}(X-Y)=0$

Boundary conditions:

$Z=0 \rightarrow\left\{\begin{array}{l}\left(\frac{U_{c}}{E_{c}}\right)\left(1-X^{0}\right)=-\left.\frac{d X}{d Z}\right|_{0} \\ \left.\frac{d Y}{d Z}\right|_{0}=0 \rightarrow Y^{0}=Y^{\text {out }}\end{array}\right.$

$Z=1 \rightarrow\left\{\begin{array}{l}\left.\frac{d X}{d Z}\right|_{1}=0 \rightarrow X^{1}=X^{\text {out }} \\ \left(\frac{U_{d}}{E_{d}}\right)\left(Y^{1}\right)=-\left.\frac{d X}{d Z}\right|_{1}\end{array}\right.$

\subsection{Forward Mixing Model (FMM)}

$\frac{d X}{d Z}-\frac{1}{P e_{c}} \frac{d^{2} X}{d Z^{2}}+\Omega \sum_{i=1}^{N} N T U_{o d, i}\left(X-Y_{i}\right)=0$

$\frac{d Y_{i}}{d Z}+\frac{N T U_{o d, i}}{g_{i}}\left(X-Y_{i}\right)=0 \quad(i=1,2, \ldots N)$

$\mathrm{g}_{\mathrm{i}}$ in Eq. (14) is the dynamic drop size distribution as follow:

$g_{i}=\frac{f_{i} u_{i}}{\sum_{j=1}^{N} f_{j} u_{j}}$

$\mathrm{u}_{\mathrm{i}}$ in Eq. (15) is drops velocity that can be calculated using Eq. (16)

$u_{i}=\frac{d_{i}}{d_{43}} U_{\text {slip }}-\frac{U_{c}}{1-\phi}$

Boundary conditions: 


$$
\begin{aligned}
& Z=0 \rightarrow \begin{cases}\left(\frac{U_{c}}{E_{c}}\right)\left(1-X^{0}\right)=-\left.\frac{d X}{d Z}\right|_{0} \\
Y_{i}^{0}=Y_{i}^{\text {out }} \quad(i=1,2, \ldots N)\end{cases} \\
& Z=1 \rightarrow \begin{cases}\left.\frac{d X}{d Z}\right|_{1}=0 & \rightarrow X^{1}=X^{\text {out }} \\
Y_{i}^{1}=Y^{\text {in }}=0 & (i=1,2, \ldots N)\end{cases}
\end{aligned}
$$

\section{Experimental}

\subsection{Material and Apparatus}

The synthetic chloride solution was created by dissolving $600 \mathrm{ppm}$ of supplied $\mathrm{ZnCl} 2$ from Merck Company with $99 \%$ purity in distilled water. The used commercial extractant in the experiments, namely $\mathrm{D}_{2} \mathrm{EHPA}$ is purchased from Sigma-Aldrich without any purification. The aqueous phase $\mathrm{pH}$ was set using ammonium solution of $25 \%$ purity and hydrochloric acid with a purity of 37\% from Merck Company. A digital pH meter (Sartorius Basic meter PB-11) has been utilized to count the number of hydrogen ions. $\mathrm{Zn}$ (II) concentration in the aqueous phase was measured by UV-visible spectroscopy (UNICO model). Then, the concentration of metal ions in the organic phase has been calculated via the mass balance method. In the column experiments, all the solvent extraction runs were performed at room temperature and atmospheric pressure in which the concentration of $\mathrm{D}_{2}$ EHPA equal to $0.1 \mathrm{M}$. Also, metal separating from the loaded organic phase was conducted by $1 \mathrm{M}$ of hydrochloric acid solution as a stripping agent.

\subsection{Physical properties}

In this study, densities of the continuous and the dispersed phases have calculated by the pycnometer methodology. The viscosities of both fluids were also determined via DVI-Prime viscometer. The interfacial tensions in extraction and stripping stages were obtained with a Krüss tensiometer. Literature survey expresses that the measurement of physical properties especially 
interfacial tension is approximately invalid due to uncertainty existence along the column ${ }^{39}$. As a result, the mean values of $\mathrm{Zn}$ (II) concentration in the continuous and dispersed phases at the inlet and outlet of the MRDC column were obtained to remove the measurement errors in this phenomenon. Table 1 lists the physical properties of dispersed and continuous phases for both mass transfer directions.

\section{Table 1}

\subsection{Measurement of hydrodynamic parameters}

The aqueous phase containing zinc chloride solution was first pumped into the main section of the extractor, and then the mass transfer device was filled by the dispersed phase for performing the solvent extraction process. By considering the digital camera (Nikon D5000), droplets size has been determined by a photographic approach in which ImageJ software has been applied to interpret the image analysis. Photograph analysis method using this software is completely described in $\operatorname{Ref}^{40}$. The following relation is presented to obtain the equivalent diameter of the non-spherical droplets, where $\mathrm{d}_{1}$ and $\mathrm{d}_{2}$ indicate the major and minor axes, respectively:

$d_{e}=\left(d_{1}^{2} d_{2}\right)^{1 / 3}$

The average droplet size has then calculated as follows:

$d_{32}=\frac{\sum_{i=1}^{n} n_{i} d_{i}^{3}}{\sum_{i=1}^{n} n_{i} d_{i}^{2}}$

In this analysis, the inlet and outlet valves of the MRDC column were rapidly closed while the steady-state situations were established. The continuous and dispersed phases were separated over time from each other and then the holdup values were calculated by the following equation:

$\varphi=\frac{\forall_{d}}{\forall_{d}+\forall_{c}}$ 
The relative speed of dispersed phase drops within the column is described as the slip velocity. This hydrodynamic variable is defined as the linear velocity summation of both fluids during the operational situations that are given as below:

$V_{S}=\frac{V_{d}}{\varphi}+\frac{V_{c}}{(1-\varphi)}$

The interfacial area was also measured for $\mathrm{Zn}$ (II) reaction in the extraction and stripping stages by the following equation:

$a=\frac{6 \varphi}{d_{32}}$

\subsection{MRDC column experiments}

The solvent extraction behavior for zinc extraction in both mass transfer directions has been investigated in the MRDC column with the perforated configuration, and the schematic flow diagram of this column is shown in Fig 1. Mixing of fluids is accomplished by the discs of 70 $\mathrm{mm}$ diameter located at the center of the column and these discs are moved by an electric stimulant by applying the variable gearbox. The column length consists of 43 stages. The internal parts of the column for both settled sections are built of SS316. This column consists of internal diameter and active section equal to $113 \mathrm{~mm}$ and $1430 \mathrm{~mm}$, respectively. The distributions of the dispersed and continuous phases are posited at the bottom and top of the column, respectively. Torab-Mostaedi and co-workers have completely described the variation of the interface is

regulated via the optical sensor in the specific area of the liquid-liquid extraction column ${ }^{41}$. It should be mentioned that column conditions to conduct the experiments were far from flooding points.

\section{Fig.1}




\section{Results and discussion}

The dispersed phase holdup, droplets behavior, and slip velocity are essential to study the mass transfer characteristics in the continuous extraction columns. Prediction of the mass transfer data using the mentioned models has been examined to interpret the column performance under chemical reaction conditions. In this research, each class's mass transfer coefficients have been determined with the technique of fitting concentration profiles. Also, the concentration profiles of organic and aqueous phases have been evaluated step-by-step through the column length. The quantities of the continuous and dispersed phases in these models are represented by $\mathrm{X}$ and $\mathrm{Y}$, respectively. The experimental data for the holdup of the dispersed phase, average droplet diameter, slip velocity, zinc transport efficiency, and the values of AARE for four theoretical models are listed in Tables 2 and 3 for the extraction and stripping stage, respectively.

\section{Table 2}

\section{Table 3}

The poor predictive capability of PFM is referred to the fact that the MRDC column performance for reactive extraction systems does seriously deviate from ideal plug conditions. In these conditions, the modified models by considering the non-ideality state, namely the axial dispersion and backflow mathematical models have been utilized to reduce some errors. When the reactive mass transfer rates are calculated by these models, the quantities of the absolute average relative error for $\mathrm{X}$ and $\mathrm{Y}$ parameters decrease. As can be seen, the relative deviation error of mass transfer coefficients is highly decreased in both mass transfer directions by considering the forward mixing model due to adding the impact of droplet size distribution. At constant inlet phase rates, Fig. 2 shows the rotor speed impacts on the holdup values, mean drop size, and slip velocity in the extraction and stripping stages. The break-up of the large droplets 
into smaller ones has occurred at higher rotor speed due to increasing the shear forces. Consequently, this phenomenon leads to enhancement of residence time of drops along the extraction column, which the holdup values enhance with an increase in the rotor speed. The slip velocity decreases with an enhancement in the disc speed based on the decrement in the mean drop size and dispersed phase at higher rotor speeds. Dispersed phase holdup in the extraction stage is higher than the stripping stage at similar operating situations. The resistance to the mass transfer direction and the interfacial tension deviation leads to appear this event. It was also found that the slip velocity and average droplet size in the extraction system are lower than in the stripping system. The hydrodynamic parameters for reactive systems against the continuous phase rate are indicated in Fig.3. As demonstrated in this figure, the continuous phase rate by applying the various range between 16 and $34 \mathrm{~L} / \mathrm{h}$ have an insufficient impact on the trend of the hydrodynamic parameters accordingly, the effect of this parameter can be neglected. Fig. 4 shows the effect of dispersed phase rate on the hydrodynamic parameters such as dispersed phase holdup, slip velocity, and drop size. By increasing the flow rate of the dispersed phase, the holdup values and mean drop size are slightly increased at both stages because of improving the number of droplets through further increment in the dispersed phase rates. In addition, the slip velocity function directly depends on the holdup volume fraction and average drop size in which the obtained quantities for this parameter are developed with an increase in the dispersed phase rate.

\section{Fig.2}

Fig.3

Fig.4 
The measurement of droplet's behavior is a critical function due to creating the distribution of the corresponding droplets in the analysis of the taken photos based on the mixture of the dispersed and continuous phases ${ }^{42}$. The variation of drop size distribution in terms of the rotor speed for extraction and stripping stages is depicted in Fig.5. Turbulent situations at the high agitation speed lead to establishing the tiny drops in which the distribution curve shifts to the left side and becomes narrower. Compared with the extraction stage, the stripping stage has a wider distribution for drop behavior, because the interfacial tension performance prevents coalescence rate at the extraction stage and improves for generating larger droplets at the stripping stage. In this study, no remarkable variation for drop size distribution observes with changes in the continuous and dispersed phase rates. Hence, the dependences of droplet distribution on both fluids flow rates were negligible for zinc solvent extraction in the MRDC column. The output results in the mentioned extractor are sufficiently in agreement with the previously published works in rotating disc contactor columns ${ }^{43,44}$.

\section{Fig.5}

The experimental results and numerical modeling based on the forward mixing approach indicated that the relative deviations in the calculation of concentration profiles are acceptable owing to the perforated structure of discs in this column. As a result, the profile changes using the curve fitting process and forward mixing model are shown in Fig.6. It was observed that the predictive of actual data with this model based on adding the effects of the droplet size distribution were near enough to the regression line.

\section{Fig.6}

The numerical evaluations for axial dispersion coefficients based on the continuous and dispersed phase with changes in the operational variables such as rotor speed and phase flow 
rates are illustrated in Figs. 7 and 8, respectively. Improvement in the values of $E_{c}$ and $E_{d}$ is observed by enhancing the rotor speed in the extraction and stripping stages. Increasing the system turbulence leads to enhancing the droplet density and the vortex development in the continuous phase by an increase in the rotor speed, and consequently, the continuous phase axial dispersion coefficients are improved by this parameter. The solvent phase droplets are formed uniformly with the increasing rate of the continuous phase, and the conflict of drops with the internal sections of the equipment enhances. Therefore, the calculated axial dispersion coefficient for the continuous phase from axial dispersion and forward mixing models enhances by improvement in the range of this parameter. Drops accumulation within the column occurs at a higher flow rate of the dispersed phase, which this event gradually shifts the system behavior to the densely packed state with droplets. Therefore, descending variations in the axial dispersion coefficient based on the dispersed phase are observed by applying high flow rates for the dispersed phase. According to Fig.8(b), the values of $E_{d}$ are reduced with changes in the continuous phase rate in both mass transfer directions due to increasing the drag force of drops and decreasing the slip velocity. The impact of dispersed phase rate on the values of dispersed phase axial dispersion coefficient showed that the amount of $E_{d}$ enhances with increasing this parameter from 16 to $28 \mathrm{~L} / \mathrm{h}($ Fig.8(c)).

\section{Fig.7}

Fig.8

Fig.9 indicates the impact of operating parameters on the backflow mixing coefficient of the continuous phase. The surface tension values in the stripping stage are more than its quantities in the extraction stage that leads to creating further inner circulation inside the droplets, and eventually the backflow coefficient of the stripping stage is greater in comparison to the 
extraction stage. Also, another reason for this behavior is related to the reaction interactions of zinc ions by the extractant and stripping agents. The mathematical modeling shows that the rotor speed on the backflow coefficients is similar to axial dispersion coefficients. It can be observed that the calculated continuous phase coefficient by the backflow mixing model enhances from 16 to $34 \mathrm{~L} / \mathrm{h}$ for extraction and stripping stages. Because the drag forces of droplets with the aqueous phase are developed and non-linear movement paths are significantly formed by increasing the continuous phase flow rate. The relative velocity of drops in the aqueous phase is slightly increased by increasing the flow rate of the dispersed phase, which can augment the inertia force of drops. Thereby, $\alpha(-)$ decreases at higher values of $\mathrm{Q}_{\mathrm{d}}(\mathrm{L} / \mathrm{h})$ along the extraction column. The influence of operational parameters on the backflow coefficient based on the dispersed phase is portrayed in Fig.10. Quantities of the $\beta$ (-) are also developed by increasing and decreasing the flow rate for dispersed and continuous phases, respectively.

\section{Fig.9}

\section{Fig.10}

In this study, the forward mixing model has been used for the numerical solution of mass transfer coefficients owing to the best performance among other mathematical models (see in Table 4). The numerical results to interpret the reactive mass transfer rate as a function of rotor speed, continuous and dispersed phases flow rate are represented in Fig.11. It was found that the rotor speed is one of the critical operating variables in the MRDC column for reactive systems. This parameter has a significant effect on the dispersed phase holdup, mean drop size, interfacial area, and slip velocity in which the surface area increment for performing the chemical reaction causes the extraction system in this column to move towards the maximum separation process. Although the rigid state creation for solvent phase droplets at high rotor speeds causes a decrease 
in the overall mass transfer coefficients, increasing the required surface area provides high efficiency for the overall mass transfer rates. As mentioned, no remarkable effect on the dispersed phase and mean drop size was observed with changes in the flow rate of the dispersed and continuous phases. Nonetheless, the impact of holdup quantities on the required area is more than the average drop size. Consequently, the interfacial area for zinc (II) chemical reaction in the extraction and stripping stages slightly increases with an enhancement in the flow rate of both phases. The mass transfer coefficients improve due to inner circulation within the drops. Thus, the mass transfer performance is increased at higher values of $\mathrm{Q}_{\mathrm{d}}$ and $\mathrm{Q}_{\mathrm{c}}$. According to this figure, the output results indicate that the effect of rotor speed and dispersed phase rate on the reactive mass transfer data is more significant than the continuous phase rate.

\section{Fig.11}

\section{Table 4}

\section{Conclusion}

In this study, the MRDC column performance for Zn (II) extraction from chloride solution has been examined. The operational conditions of the mentioned column were reviewed by changing the rotor speed and the flow rate of the inlet phases. The desirability achieves for zinc transport efficiency in both mass transfer directions with an increase in the operating parameters. Compared with the stripping stage, the higher holdup values, smaller droplet size, narrower drop distribution, and lower slip velocity are obtained in the extraction stage. The different theoretical models such as PFM, BFM, ADM, and FMM were used to calculate the mass transfer coefficients under reactive conditions in this column. The curve fitting method by four models and comparison with mass transfer data develops an appropriate basis for the extraction and stripping of zinc metal. The relative deviation values for these models show that the forward 
mixing model by adding the size distribution of droplets is in good agreement with the reactive mass transfer data. Concentration profiles, axial dispersion coefficients, and backflow mixing coefficients were qualitatively represented by evaluating the breakage and coalescence of droplets. The continuous phase coefficients for axial dispersion and backflow mixing models improve by enhancing the continuous phase rate and reducing the dispersed phase rate. The mathematical modeling findings expressed that the rotor speed has a substantial effect on reactive mass transfer rates and weaker, was the impact of continuous phase rate. In this sense, the evaluation of volumetric overall mass transfer coefficients by applying the forward mixing model would be beneficial to the design and scale-up of the MRDC column for heavy metal extraction.

\section{Nomenclature}

a Specific surface area per unit volume $\left(6 \varphi / d_{32}\right)(1 / m)$

$\mathrm{d} \quad$ Drop diameter ( $\mathrm{m}$ or $\mathrm{mm})$

$\mathrm{d}_{32} \quad$ Sauter mean drop diameter $(\mathrm{mm})$

$\mathrm{d}_{43} \quad$ Mean diameter $(\mathrm{m})$

E Axial dispersion coefficient $\left(\mathrm{cm}^{2} / \mathrm{s}\right)$

$f \quad$ Volumetric drops size distribution (-)

g Dynamic drop size distribution (-)

H Height of column (m)

K Overall mass transfer coefficient $(\mathrm{m} / \mathrm{s})$

$\mathrm{N} \quad$ Agitator speed (rpm)

n Number of drops (-) 
$\mathrm{N}_{\mathrm{c}} \quad$ Number of cross-sections in numerical solution (-)

$\mathrm{N}_{\mathrm{d}} \quad$ Number of drop classes (-)

$\mathrm{N}_{\mathrm{s}} \quad$ Number of sampling cross-sections (-)

P Drop size distribution

Q Volume flow rate $(\mathrm{L} / \mathrm{h})$

$\mathrm{r} \quad$ Mass transfer rate from ith class drops $(\mathrm{kg} / \mathrm{s})$

R Total mass transfer rate $(\mathrm{kg} / \mathrm{s})$

S Cross-sectional area of the column $\left(\mathrm{m}^{2}\right)$

$\mathrm{t} \quad$ Residence time of drops (s)

u Drop velocity $(\mathrm{m} / \mathrm{s})$

U Superficial velocity $(\mathrm{Q} / \mathrm{S})(\mathrm{m} / \mathrm{s})$

$\mathrm{U}_{\text {slip }} \quad$ Slip velocity $\left(\mathrm{U}_{\mathrm{c}} /(1-\varphi)+\mathrm{U}_{\mathrm{d}} / \varphi\right)(\mathrm{m} / \mathrm{s})$

$\mathrm{V} \quad$ Volume of phases $\left(\mathrm{m}^{3}\right)$

$\mathrm{x} \quad$ Mass fraction of solute in continuous phase (-)

y Mass fraction of solute in dispersed phase (-)

z Height variable (m)

\section{Dimensionless symbols}

NTU Number of transfer unit $\left(\mathrm{K}_{\text {odaH}} \mathrm{a} / \mathrm{U}_{\mathrm{d}}\right)$

$\mathrm{p} \quad$ Slope of the concentration equilibrium equation $\left(y=\mathrm{p}^{*} \mathrm{x}+\mathrm{q}\right)$

Pe Peclet number (HU/E)

$\mathrm{q} \quad$ Constant of the concentration equilibrium equation $\left(y=p^{*} x+q\right)$

$\mathrm{X}$ Continuous phase concentration $\left(\left(\mathrm{x}-\mathrm{x}^{*}{ }_{\text {out }}\right) /\left(\mathrm{x}_{\text {in }}-\mathrm{X}^{*}{ }_{\text {out }}\right)\right)$

Y Dispersed phase concentration $\left(\left(\mathrm{y}-\mathrm{y}_{\text {in }}\right) /\left(\mathrm{y}^{*}{ }_{\text {out }}-\mathrm{y}_{\text {in }}\right)\right)$ 
$\mathrm{Z} \quad$ Height $(\mathrm{Z}=\mathrm{z} / \mathrm{H})$

$\Omega \quad$ Constant $\left(p U_{d} \rho_{d} / U_{c} \rho_{c}\right)$

\section{Greek symbols}

$\mu \quad$ Viscosity $(\mathrm{kg} / \mathrm{m} . \mathrm{s})$

$\rho \quad$ Density $\left(\mathrm{kg} / \mathrm{m}^{3}\right)$

$\sigma \quad$ Interfacial tension between two phases $(\mathrm{N} / \mathrm{m})$

$\varphi \quad$ Dispersed phase holdup (-)

$\psi \quad$ Slop of mass transfer coefficent equation (-)

\section{Subscripts/Superscripts}

* Equilibrium concentration

c Continuous phase

d Dispersed phase

i Drop class

in Inlet to the column

j Cross-section

out Outlet from the column

\section{Abbreviations}

AARE Average Absolute Relative Error

ADM Axial Dispersion Model

BFM Back Flow Model

DSD Drop Size Distribution

FMM Forward Mixing Model

PRDC Perforated Rotating Disk Contactor 


\section{LLE Liquid-Liquid Extraction}

\section{References}

1. Leclerc, N., Meux, E. \& Lecuire, J.M. Hydrometallurgical extraction of zinc from zinc ferrites. Hydrometallurgy 70, 175-183 (2003).

2. Deep, A. \& de Carvalho, J. M. Review on the recent developments in the solvent extraction of zinc. Solvent Extract. Ion Exch. 26, 375-404 (2008).

3. Jha, M. K., Kumar, V. \& Singh, R. Solvent extraction of zinc from chloride solutions. Solvent Extract. Ion Exch. 20, 389-405 (2002).

4. Alyüz, B. \& Veli, S. Kinetics and equilibrium studies for the removal of nickel and zinc from aqueous solutions by ion exchange resins. J. Hazard. Mater. 167, 482-488 (2009).

5. Sayilgan, E., Kukrer, T., Yigit, N., Civelekoglu, G. \& Kitis, M. Acidic leaching and precipitation of zinc and manganese from spent battery powders using various reductants. $J$. Hazard Mater. 173, 137-143 (2010).

6. Benedict, M., Pigford, T. H. \& Levi, H.W. Nuclear Chemical Engineering. McGraw-Hill Education, New York (1981).

7. Cheng, C. Y., Purification of synthetic laterite leach solution by solvent extraction using D2EHPA. Hydrometallurgy 56, 369-386 (2000).

8. Nathsarma, K. \& Devi, N. Separation of Zn (II) and Mn (II) from sulphate solutions using sodium salts of D2EHPA, PC88A and Cyanex 272. Hydrometallurgy 84, 149-154 (2006).

9. Baba, A. A. \& Adekola, F. A. Beneficiation of a Nigerian sphalerite mineral: solvent extraction of zinc by Cyanex® 272 in hydrochloric acid. Hydrometallurgy 109, 187-193 (2011). 
10. Alguacil, F. J., Cobo, A. \& Caravaca, C. Study of the extraction of zinc (II) in aqueous chloride media by Cyanex 302. Hydrometallurgy 31, 163-174 (1992).

11. El Dessouky, S., El-Nadi, Y., Ahmed, I., Saad, E. \& Daoud, J. Solvent extraction separation of $\mathrm{Zn}$ (II), Fe (II), Fe (III) and Cd (II) using tributylphosphate and CYANEX 921 in kerosene from chloride medium. Chem. Eng. Process 47, 177-183 (2008).

12. Jafari, H., Abdollahi, H., Gharabaghi, M. \& Balesini, A. A. Solvent extraction of zinc from synthetic Zn-Cd-Mn chloride solution using D2EHPA: Optimization and thermodynamic studies. Sep. Purif. Technol. 197, 210-219 (2018).

13. Alamdari, E. K., Moradkhani, D., Darvishi, D., Askari, M. \& Behnian, D. Synergistic effect of MEHPA on co-extraction of zinc and cadmium with DEHPA. Miner. Eng. 17, 89-92 (2004).

14. Jia, Q., Li, D. \& Niu, C. Synergistic extraction of zinc (II) by mixtures of primary amine N1923 and Cyanex272. Solvent Extract. Ion Exch. 20, 751-764 (2002).

15. Ali, A., Ahmad, I. \& Daoud, J. CYANEX 272 for the extraction and recovery of zinc from aqueous waste solution using a mixer-settler unit. Sep. Purif. Technol. 47, 135-140 (2006).

16. Godfrey, J. C. \& Slater, M. J. Liquid-liquid extraction equipment. Wiley, New York (1994).

17. Amani, P., Safdari, J., Gharib, A., Badakhshan, H. \& Mallah, M. H. Mass transfer studies in a horizontal pulsed sieve-plate column for uranium extraction by tri-n-octylamine using axial dispersion model. Prog. Nucl. Energy 98, 71-84 (2017).

18. Soltanali, S., Ziaie-Shirkolaee, Y., Amoabediny, G., Rashedi, H., Sheikhi, A. \& Chamanrokh, P. Hydrodynamics and mass transfer performance of rotating sieved disc contactors used for reversed micellar extraction of protein. Chem. Eng. Sci. 64, 2301-2306 (2009). 
19. Hemmati, A., Torab-Mostaedi, M., Shirvani, M. \& Ghaemi, A. A study of drop size distribution and mean drop size in a perforated rotating disc contactor (PRDC). Chem. Eng. Res. Des. 96, 54-62 (2015).

20. Asadollahzadeh, M., Torab-Mostaedi, M., Shahhosseini, S. \& Ghaemi, A. Holdup, characteristic velocity and slip velocity between two phases in a multi-impeller column for high/medium/low interfacial tension systems. Chem. Eng. Process 100, 65-78 (2016).

21. Napeida, M., Haghighi Asl, A., Safdari, J. \& Torab-Mostaedi, M. Holdup and characteristic velocity in a Hanson mixer-settler extraction column. Chem. Eng. Res. Des. 88, 703-711 (2010). 22. Shakib, B., Torab-Mostaedi, M., Outokesh, M. \& Asadollahzadeh, M. Mass transfer evaluation in a multi-impeller extractor for reactive Mo (VI) extraction from aqueous Sulphate solution by utilizing coupling of acid and solvating Extractants. Heat Mass Trans. 56, 1995-2006 (2020).

23. Amanabadi, M., Bahmanyar, H., Zarkeshan, Z. \& Mousavian, M. A. Prediction of effective diffusion coefficient in rotating disc columns and application in design. Chinese J. Chem. Eng. 17, 366-372 (2009).

24. Vermijs, H. \& Kramers, H. Liquid-liquid extraction in a "rotating disc contactor". Chem. Eng. Sci. 3, 55-64 (1954).

25. Ghalehchian, J. \& Slater, M. A possible approach to improving rotating disc contactor design accounting for drop breakage and mass transfer with contamination. Chem. Eng. J. 75, 131-144 (1999).

26. Murugesan, T. \& Regupathi, I. Prediction of continuous phase axial mixing in rotating disc contactors. J. Chem Eng. Japan 37, 1293-1302 (2004). 
27. Wang, Y., Fei, W., Sun, J. \& Wan, Y. Hydrodynamics and mass transfer performance of a modified rotating disc contactor (MRDC). Chem. Eng. Res. Des. 80, 392-400 (2002).

28. Torab-Mostaedi, M. \& Asadollahzadeh, M. Mass transfer performance in an asymmetric rotating disc contactor. Chem. Eng. Res. Des. 94, 90-97 (2015).

29. Hemmati, A., Shirvani, M., Torab-Mostaedi, M. \& Ghaemi, A. Mass transfer coefficients in a perforated rotating disc contactor (PRDC). Chem. Eng. Process 100, 19-25 (2016).

30. Shakib, B., Torkaman, R., Torab-Mostaedi, M. \& Asadollahzadeh, M. Revealing mass transfer and hydrodynamic effects in a PRDC column by using the integration of extraction and separation for molybdenum and tungsten ions from aqueous solution. Chem. Pap. 74, 4295-4313 (2020).

31. Asadollahzadeh, M., Hemmati, A., Torab-Mostaedi, M., Shirvani, M., Ghaemi, A. \& Mohsenzadeh, Z. Use of axial dispersion model for determination of Sherwood number and mass transfer coefficients in a perforated rotating disc contactor. Chinese J. Chem. Eng. 25, 53-61 (2017).

32. Khanramaki, F., Torkaman, R., Shirani, A. S. \& Safdari, J. Experimental study on the mass transfer performance of a horizontal pulsed column for uranium recovery from a sulfate leach liquor with Alamine 336 using mathematical model. Chem. Eng. Res. Des. 151, 40-55 (2019).

33. Saremi, M., Torkaman, R., Safdari, J., Gharib, A. \& Asadollahzadeh, M. A novel model for mass transfer evaluation in horizontal pulsed column by coupling the effects of dispersed phase non-uniformity and continuous phase back mixing. Inter. Commun. Heat Mass Tras. 122, 105145 (2021).

34. Thornton, J. D., Science and Practice of Liquid-liquid Extraction. Oxford University Press, New York, (1992). 
35. Hemmati, A., Shirvani, M., Torab-Mostaedi, M. \& Ghaemi, A. Hold-up and flooding characteristics in a perforated rotating disc contactor (PRDC). RSC Adv. 5, 63025-63033 (2015). 36. Hemmati, A., Ghaemi, A. Utilizing RSM for experimental modeling of mass transfer coefficients in a perforated rotating disc contactor (PRDC). Heat Mass Tran., Article in Press (2021).

37. Porto, A., Sarubbo, L., Lima-Filho, J., Aires-Barros, M., Cabral, J. \& Tambourgi, E. Hydrodynamics and mass transfer in aqueous two-phase protein extraction using a continuous perforated rotating disc contactor. Bioprocess Eng. 22, 215-218 (2000).

38. Shakib, B., Torkaman, R., Torab-Mostaedi, M. \& Asadollahzadeh, M. Mass transfer studies in RDC column by the coupling effects of perforated structure and reactive extraction of Mo (VI) and W (VI) from sulfate solution. Inter. Commun. Heat and Mass Trans. 118, 104903 (2020).

39. Khanramaki, F., Safdari, J., Shirani, A. S. \& Torkaman, R. Experimental study on hold-up, characteristic and slip velocities in a horizontal pulsed sieve-plate column and uranium reactive extraction condition in aqueous phase. Progress Nucl. Energy 109, 159-170 (2018).

40. Shakib, B., Torkaman, R., Torab-Mostaedi, M. \& Asadollahzadeh, M. The performance of pulsed scale-up column for permeable of selenium and tellurium ions to organic phase, case study: Disc and doughnut structure. Chem. Eng. Process 157, 108042 (2020).

41. Torab-Mostaedi, M., Ghaemi, A. \& Asadollahzadeh, M. Flooding and drop size in a pulsed disc and doughnut extraction column. Chem. Eng. Res. Des. 89, 2742-2751 (2011).

42. Asadollahzadeh, M., Torab-Mostaedi, M., Torkaman, R. Drop behavior in a pilot plant asymmetric rotating disc extraction column for three various liquid-liquid systems. Chem. Eng. Res. Des. 138, 366-373 (2018). 
43. Moreira, E., PIMENTA, L. M., CARnEIRO, L. L., FARIA, R. C., MANSUR, M. B., RIBEIRO, J. \& CLÁUDIO P. Hydrodynamic behavior of a rotating disc contactor under low agitation conditions. Chem. Eng. Commun. 192, 1017-1035 (2005).

44. Asadollahzadeh, M., Torkaman, R. \& Torab-Mostaedi, M. Coupling minimum cross-entropy model with experimental data to determine the drop size distribution for lanthanum extraction in ARDC column. Sep. Sci. Technol. 56, 1071-1083 (2021). 


\section{Table Captions:}

Table 1: Characteristics of the applied chemical system in the laboratory conditions

Table 2: The comparison between the AARE values obtained by PFM, BFM, ADM, and FMM in extraction stage

Table 3: The comparison between the AARE values obtained by PFM, BFM, ADM, and FMM in stripping stage

Table 4: Comparison of volumetric overall mass transfer coefficients obtained by PFM, BFM, ADM, and FMM under different operating conditions 


\section{Figure Captions:}

Fig. 1: Schematic view of the modified rotating disk contactor with the perforated structure

Fig. 2: The effect rotor speed on hydrodynamic parameters: (a) Sauter mean diameter (b) dispersed phase holdup (c) slip velocity

Fig. 3: The effect of continuous phase flow rate on hydrodynamic parameters: (a) Sauter mean diameter (b) dispersed phase holdup (c) slip velocity

Fig. 4: The effect of dispersed phase flow rate on hydrodynamic parameters: (a) Sauter mean diameter (b) dispersed phase holdup (c) slip velocity

Fig. 5: The effect of rotor speed on volumetric drop size distribution: (a) extraction stage (b) stripping stage

Fig. 6: Comparison of laboratory concentration profiles with predicted by FMM

Fig. 7: The effect of operating parameters on continuous phase axial dispersion coefficient obtained by ADM and FMM

Fig. 8: The effect of operating parameters on dispersed phase axial dispersion coefficient obtained by ADM and FMM

Fig. 9: The effect of operating parameters on continuous phase backflow coefficient obtained by BFM

Fig. 10: The effect of operating parameters on dispersed phase backflow coefficient obtained by BFM

Fig. 11: The effect of operating parameters on volumetric overall mass transfer coefficient obtained by FMM 
Table 1: Characteristics of the applied chemical system in the laboratory conditions

\begin{tabular}{|c|c|c|c|c|}
\hline Mass transfer direction & Phase & Viscosity $\times 10^{3}(\mathrm{~kg} / \mathrm{m} . \mathrm{s})$ & Density $\left(\mathrm{kg} / \mathrm{m}^{3}\right)$ & Interfacial tension $\left(\mathrm{kg} / \mathrm{s}^{2}\right)$ \\
\hline \multirow{3}{*}{ Extraction stage $(\mathrm{c} \rightarrow \mathrm{d})$} & Aqueous phase & 0.9745 & 1011 & \multirow{3}{*}{0.0192} \\
\hline & & & & \\
\hline & Organic phase & 1.6147 & 824 & \\
\hline \multirow{3}{*}{ Stripping stage $(\mathrm{d} \rightarrow \mathrm{c})$} & Aqueous phase & 0.9831 & 1034 & \multirow{3}{*}{0.0213} \\
\hline & & & & \\
\hline & Urganic phase & 1.5699 & 889 & \\
\hline
\end{tabular}


Table 2: The comparison between the AARE values obtained by PFM, BFM, ADM, and FMM in extraction stage

\begin{tabular}{|c|c|c|c|c|c|c|c|c|c|c|c|c|c|c|c|}
\hline \multirow{3}{*}{$\begin{array}{c}\dot{0} \\
\underset{Z}{\Xi}\end{array}$} & \multirow{2}{*}{\multicolumn{3}{|c|}{ Operating Conditions }} & \multirow{2}{*}{\multicolumn{4}{|c|}{ Experimental Data }} & \multicolumn{8}{|c|}{ (AARE\%) } \\
\hline & & & & & & & & \multicolumn{2}{|c|}{ PFM } & \multicolumn{2}{|c|}{ BFM } & \multicolumn{2}{|c|}{ ADM } & \multicolumn{2}{|c|}{ FMM } \\
\hline & $\begin{array}{c}\mathrm{Q}_{\mathrm{c}} \\
(\mathrm{L} / \mathrm{h})\end{array}$ & $\begin{array}{c}\mathrm{Q}_{\mathrm{d}} \\
(\mathrm{L} / \mathrm{h})\end{array}$ & $\begin{array}{c}\mathrm{N} \\
(\mathrm{rpm})\end{array}$ & $\begin{array}{c}\mathrm{d}_{32} \\
(\mathrm{~mm})\end{array}$ & $\begin{array}{l}\phi \\
(-)\end{array}$ & $\begin{array}{c}\mathrm{U}_{\text {slip }} \\
(\mathrm{mm} / \mathrm{s})\end{array}$ & $\begin{array}{l}\text { Ext } \\
(\%)\end{array}$ & $X$ & $\mathrm{Y}$ & $X$ & $\mathrm{Y}$ & $X$ & $\mathrm{Y}$ & $X$ & $\mathrm{Y}$ \\
\hline 1 & 22 & 22 & 170 & 2.241 & 0.0846 & 7.838 & 65.42 & 4.02 & 6.87 & 3.60 & 5.53 & 6.54 & 6.65 & 3.33 & 2.64 \\
\hline 2 & 22 & 22 & 230 & 1.728 & 0.0948 & 7.098 & 75.55 & 5.49 & 5.37 & 3.89 & 4.24 & 6.83 & 5.67 & 3.16 & 3.94 \\
\hline 3 & 22 & 22 & 290 & 1.173 & 0.0972 & 6.946 & 86.77 & 8.01 & 6.26 & 6.62 & 5.45 & 7.07 & 5.34 & 5.12 & 2.63 \\
\hline 4 & 22 & 22 & 350 & 0.936 & 0.1056 & 6.452 & 95.42 & 14.47 & 11.23 & 12.78 & 9.25 & 11.47 & 10.94 & 10.64 & 9.67 \\
\hline 5 & 22 & 22 & 410 & 0.741 & 0.1195 & 5.790 & 98.85 & 15.94 & 10.10 & 10.64 & 8.89 & 12.74 & 10.83 & 9.24 & 9.36 \\
\hline 6 & 16 & 22 & 290 & 1.168 & 0.0965 & 6.805 & 84.23 & 12.59 & 14.69 & 12.41 & 8.08 & 13.49 & 9.02 & 10.16 & 8.80 \\
\hline 7 & 28 & 22 & 290 & 1.179 & 0.0983 & 7.059 & 89.52 & 21.79 & 14.47 & 15.61 & 12.36 & 19.72 & 12.70 & 12.58 & 11.29 \\
\hline 8 & 34 & 22 & 290 & 1.183 & 0.0991 & 7.194 & 90.25 & 19.23 & 16.28 & 18.41 & 14.48 & 18.16 & 15.88 & 17.36 & 14.16 \\
\hline 9 & 22 & 16 & 290 & 1.127 & 0.095 & 5.340 & 76.88 & 24.88 & 13.10 & 16.42 & 8.12 & 16.17 & 13.38 & 9.34 & 10.79 \\
\hline 10 & 22 & 28 & 290 & 1.191 & 0.0986 & 8.538 & 90.18 & 18.33 & 25.64 & 16.42 & 18.48 & 17.49 & 20.65 & 14.27 & 13.21 \\
\hline 11 & 22 & 34 & 290 & 1.217 & 0.1035 & 9.779 & 94.55 & 14.97 & 31.13 & 12.21 & 11.36 & 14.22 & 25.47 & 8.96 & 9.61 \\
\hline \multicolumn{4}{|c|}{ Average } & - & - & - & - & 14.52 & 14.10 & 11.73 & 9.66 & 13.08 & 12.41 & 9.47 & 8.74 \\
\hline
\end{tabular}


Table 3: The comparison between the AARE values obtained by PFM, BFM, ADM, and FMM in stripping stage

\begin{tabular}{|c|c|c|c|c|c|c|c|c|c|c|c|c|c|c|c|}
\hline \multirow{3}{*}{ 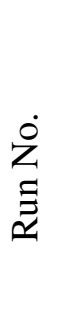 } & \multirow{2}{*}{\multicolumn{3}{|c|}{ Operating Conditions }} & \multirow{2}{*}{\multicolumn{4}{|c|}{ Experimental Data }} & \multicolumn{8}{|c|}{ (AARE\%) } \\
\hline & & & & & & & & \multicolumn{2}{|c|}{ PFM } & \multicolumn{2}{|c|}{ BFM } & \multicolumn{2}{|c|}{$\mathrm{ADM}$} & \multicolumn{2}{|c|}{ FMM } \\
\hline & $\begin{array}{c}\mathrm{Q}_{\mathrm{c}} \\
(\mathrm{L} / \mathrm{h})\end{array}$ & $\begin{array}{c}Q_{d} \\
(L / h)\end{array}$ & $\begin{array}{c}\mathrm{N} \\
(\mathrm{rpm})\end{array}$ & $\begin{array}{c}\mathrm{d}_{32} \\
(\mathrm{~mm})\end{array}$ & $\begin{array}{l}\phi \phi \\
(-)\end{array}$ & $\begin{array}{c}\mathrm{U}_{\text {slip }} \\
(\mathrm{mm} / \mathrm{s})\end{array}$ & $\begin{array}{l}\text { Ext } \\
(\%)\end{array}$ & $\mathrm{X}$ & $\mathrm{Y}$ & $X$ & Y & $\mathrm{X}$ & $\mathrm{Y}$ & $\mathrm{X}$ & Y \\
\hline 1 & 22 & 22 & 170 & 2.396 & 0.0724 & 9.076 & 85.62 & 16.98 & 10.44 & 13.67 & 8.08 & 15.14 & 7.11 & 6.83 & 11.05 \\
\hline 2 & 22 & 22 & 230 & 1.844 & 0.0786 & 8.417 & 90.03 & 17.25 & 20.92 & 14.15 & 13.22 & 16.92 & 15.81 & 7.09 & 11.89 \\
\hline 3 & 22 & 22 & 290 & 1.249 & 0.081 & 8.185 & 95.15 & 16.68 & 18.48 & 14.76 & 9.27 & 14.94 & 12.32 & 10.25 & 9.96 \\
\hline 4 & 22 & 22 & 350 & 1.014 & 0.0879 & 7.604 & 97.05 & 19.77 & 24.53 & 17.38 & 16.34 & 18.49 & 18.83 & 11.30 & 14.96 \\
\hline 5 & 22 & 22 & 410 & 0.808 & 0.0989 & 6.837 & 99.85 & 8.24 & 15.78 & 7.17 & 12.15 & 8.71 & 11.89 & 7.84 & 9.06 \\
\hline 6 & 16 & 22 & 290 & 1.241 & 0.0806 & 8.046 & 91.88 & 13.81 & 18.13 & 10.07 & 5.28 & 11.59 & 7.90 & 9.88 & 6.71 \\
\hline 7 & 28 & 22 & 290 & 1.255 & 0.0813 & 8.337 & 96.98 & 24.15 & 23.07 & 16.23 & 20.20 & 21.49 & 22.74 & 16.37 & 18.67 \\
\hline 8 & 34 & 22 & 290 & 1.258 & 0.0818 & 8.479 & 97.55 & 32.46 & 17.83 & 25.62 & 12.48 & 28.77 & 15.36 & 19.31 & 13.17 \\
\hline 9 & 22 & 16 & 290 & 1.169 & 0.0796 & 6.240 & 81.23 & 28.58 & 24.93 & 17.71 & 20.25 & 23.20 & 22.05 & 18.46 & 18.45 \\
\hline 10 & 22 & 28 & 290 & 1.269 & 0.0824 & 10.076 & 98.77 & 12.77 & 27.84 & 10.06 & 18.13 & 11.07 & 20.38 & 11.36 & 18.62 \\
\hline 11 & 22 & 34 & 290 & 1.289 & 0.0846 & 11.796 & 99.25 & 11.74 & 18.19 & 11.97 & 9.41 & 12.49 & 13.35 & 9.31 & 6.83 \\
\hline & Avc & & & - & - & - & - & 18.40 & 20.01 & 14.44 & 13.16 & 16.62 & 15.25 & 11.64 & 12.67 \\
\hline
\end{tabular}


Table 4: Comparison of volumetric overall mass transfer coefficients obtained by PFM, BFM, ADM, and FMM under different operating conditions

\begin{tabular}{|c|c|c|c|c|c|c|c|c|c|c|c|}
\hline \multirow[b]{2}{*}{ 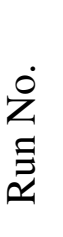 } & \multicolumn{3}{|c|}{ Operating Conditions } & \multicolumn{4}{|c|}{$\mathrm{K}_{\mathrm{od}} \mathrm{a}\left(10^{-3} 1 / \mathrm{s}\right)$ for extraction stage } & \multicolumn{4}{|c|}{$\mathrm{K}_{\mathrm{od}} \mathrm{a}\left(10^{-3} 1 / \mathrm{s}\right)$ for stripping stage } \\
\hline & $\begin{array}{c}\mathrm{Q}_{\mathrm{c}} \\
(\mathrm{L} / \mathrm{h})\end{array}$ & $\begin{array}{c}\mathrm{Q}_{\mathrm{d}} \\
(\mathrm{L} / \mathrm{h})\end{array}$ & $\begin{array}{c}\mathrm{N} \\
(\mathrm{rpm})\end{array}$ & PFM & BFM & $\mathrm{ADM}$ & FMM & PFM & BFM & $\mathrm{ADM}$ & FMM \\
\hline 1 & 22 & 22 & 170 & 0.62 & 0.64 & 0.56 & 0.77 & 2.31 & 3.38 & 3.04 & 3.45 \\
\hline 2 & 22 & 22 & 230 & 0.98 & 1.06 & 0.98 & 1.22 & 2.78 & 3.96 & 3.65 & 3.84 \\
\hline 3 & 22 & 22 & 290 & 1.94 & 2.26 & 1.84 & 2.43 & 3.40 & 4.50 & 4.21 & 4.87 \\
\hline 4 & 22 & 22 & 350 & 3.62 & 4.49 & 3.84 & 4.89 & 4.94 & 5.68 & 5.31 & 6.19 \\
\hline 5 & 22 & 22 & 410 & 5.17 & 5.55 & 4.98 & 5.78 & 6.37 & 6.74 & 6.40 & 7.02 \\
\hline 6 & 16 & 22 & 290 & 0.59 & 0.69 & 0.78 & 0.73 & 0.88 & 1.16 & 1.12 & 1.24 \\
\hline 7 & 28 & 22 & 290 & 2.21 & 4.10 & 3.96 & 4.31 & 3.80 & 5.87 & 5.50 & 6.08 \\
\hline 8 & 34 & 22 & 290 & 3.34 & 4.73 & 4.69 & 4.89 & 4.36 & 6.90 & 6.65 & 7.17 \\
\hline 9 & 22 & 16 & 290 & 1.15 & 1.82 & 1.25 & 1.92 & 1.47 & 1.91 & 1.82 & 2.24 \\
\hline 10 & 22 & 28 & 290 & 2.04 & 2.46 & 1.95 & 2.53 & 3.66 & 5.56 & 5.48 & 5.62 \\
\hline 11 & 22 & 34 & 290 & 2.97 & 2.88 & 2.16 & 2.62 & 3.76 & 5.93 & 5.84 & 6.10 \\
\hline
\end{tabular}




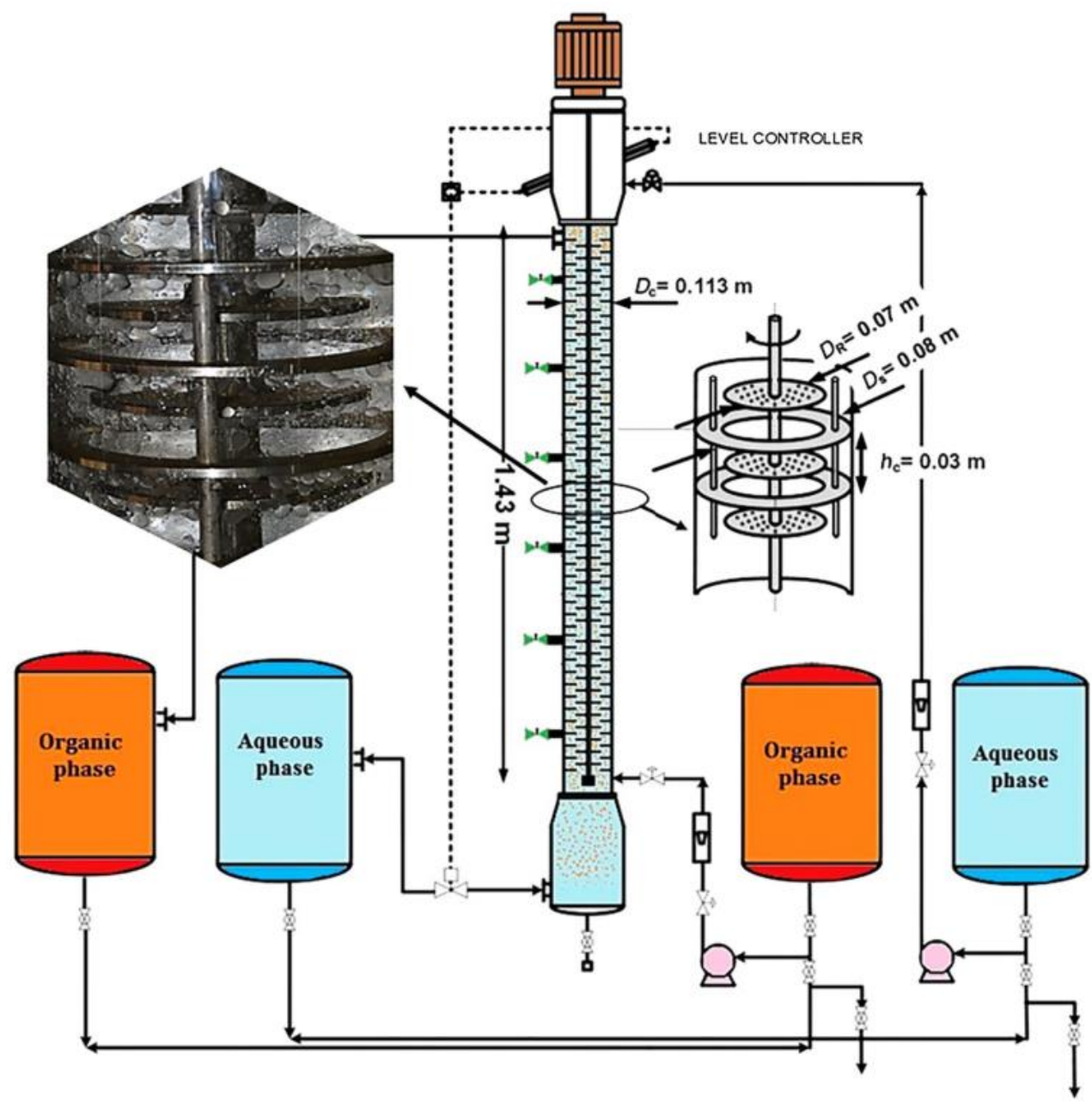

Fig. 1: Schematic view of the modified rotating disk contactor with the perforated structure 

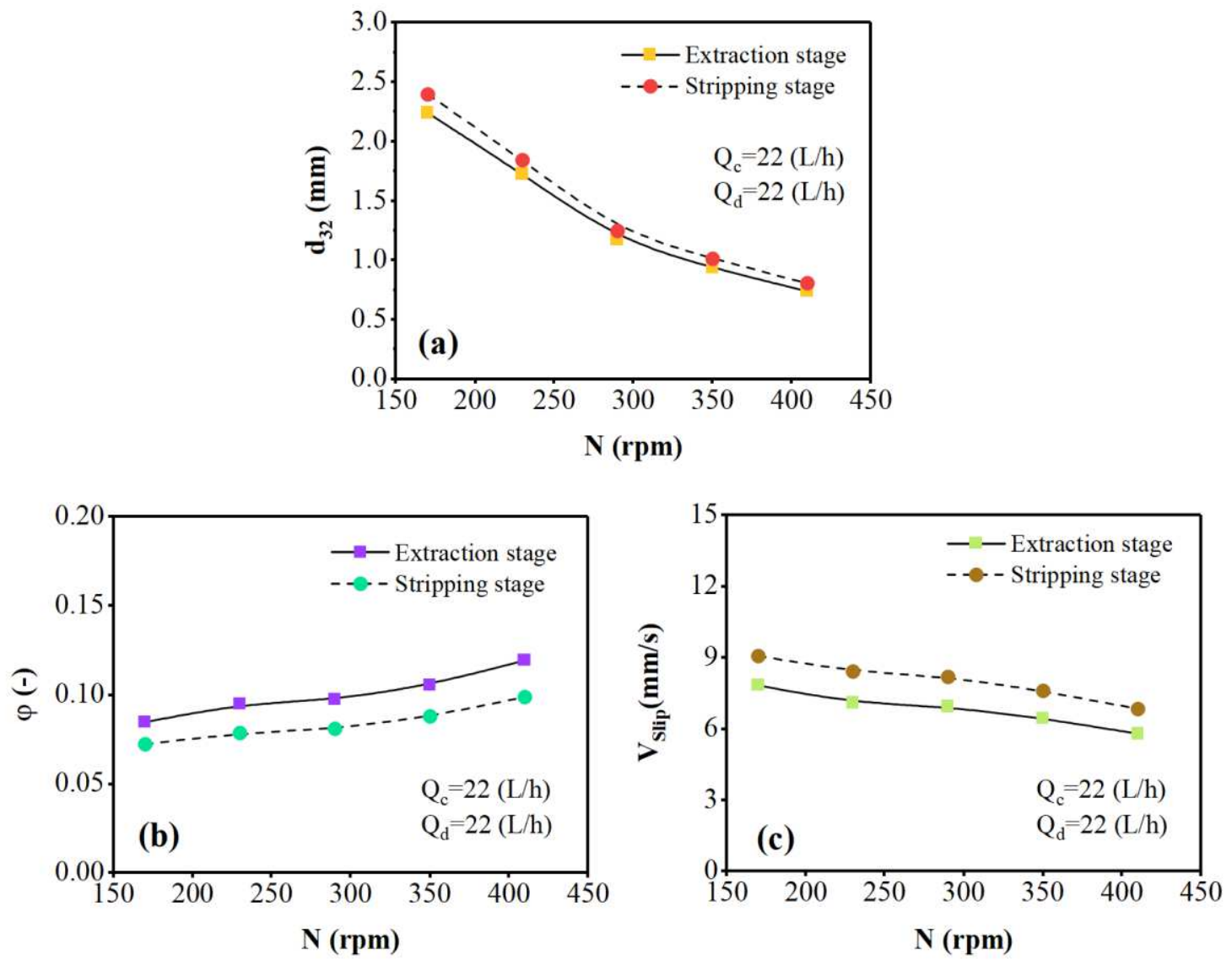

Fig. 2: The effect rotor speed on hydrodynamic parameters: (a) Sauter mean diameter (b) dispersed phase holdup (c) slip velocity 

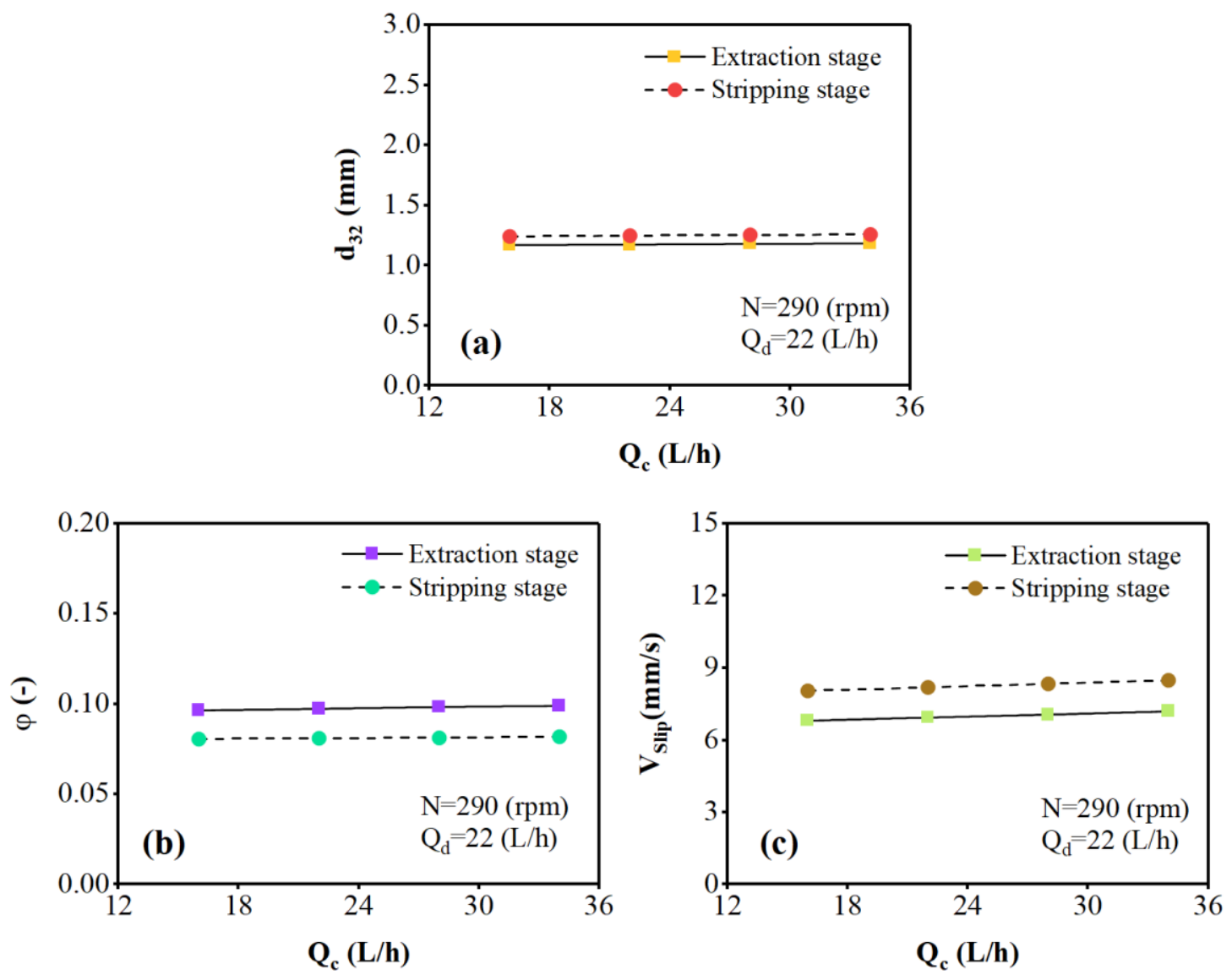

Fig. 3: The effect of continuous phase flow rate on hydrodynamic parameters: (a) Sauter mean diameter (b) dispersed phase holdup (c) slip velocity 

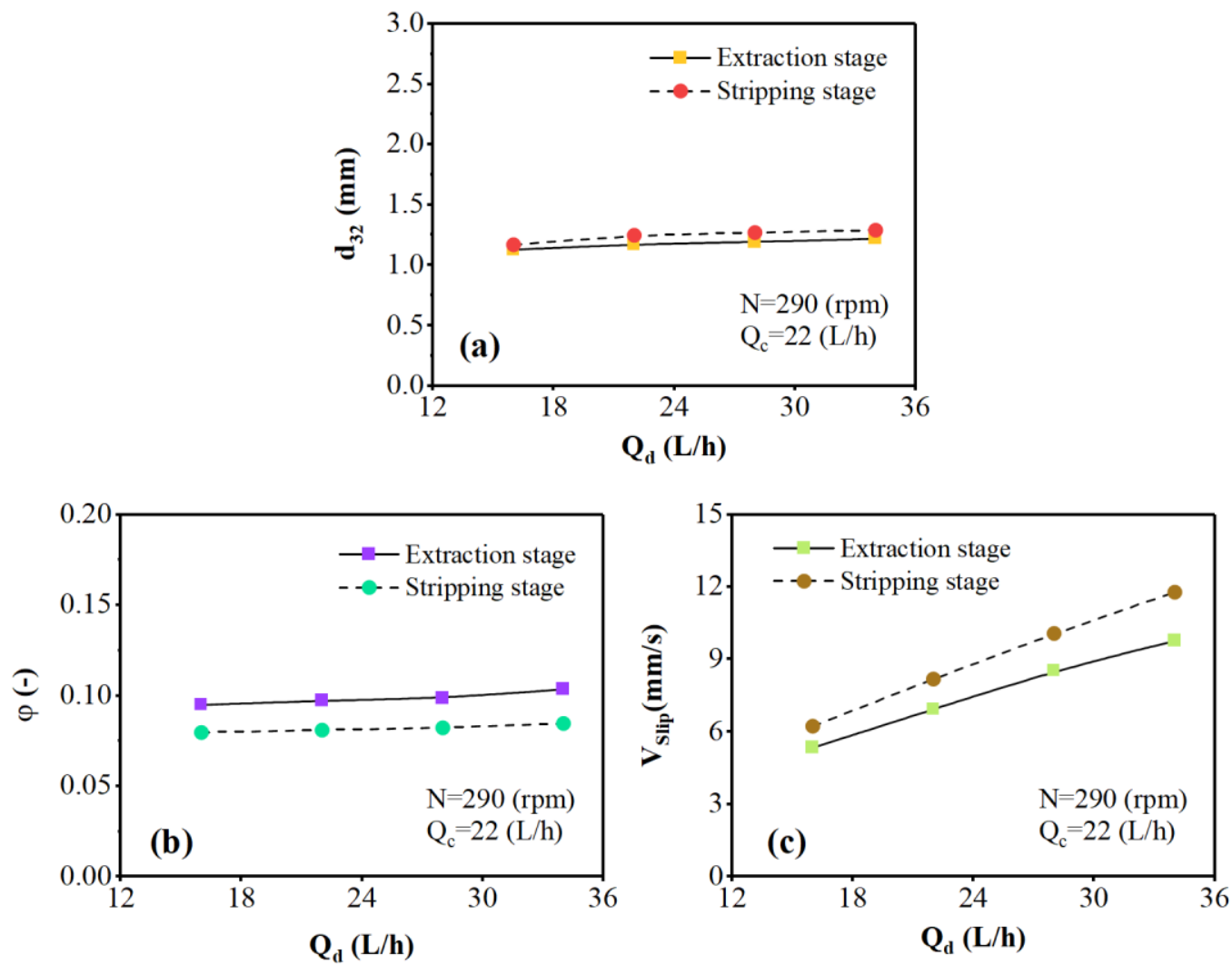

Fig. 4: The effect of dispersed phase flow rate on hydrodynamic parameters: (a) Sauter mean diameter (b) dispersed phase holdup (c) slip velocity 

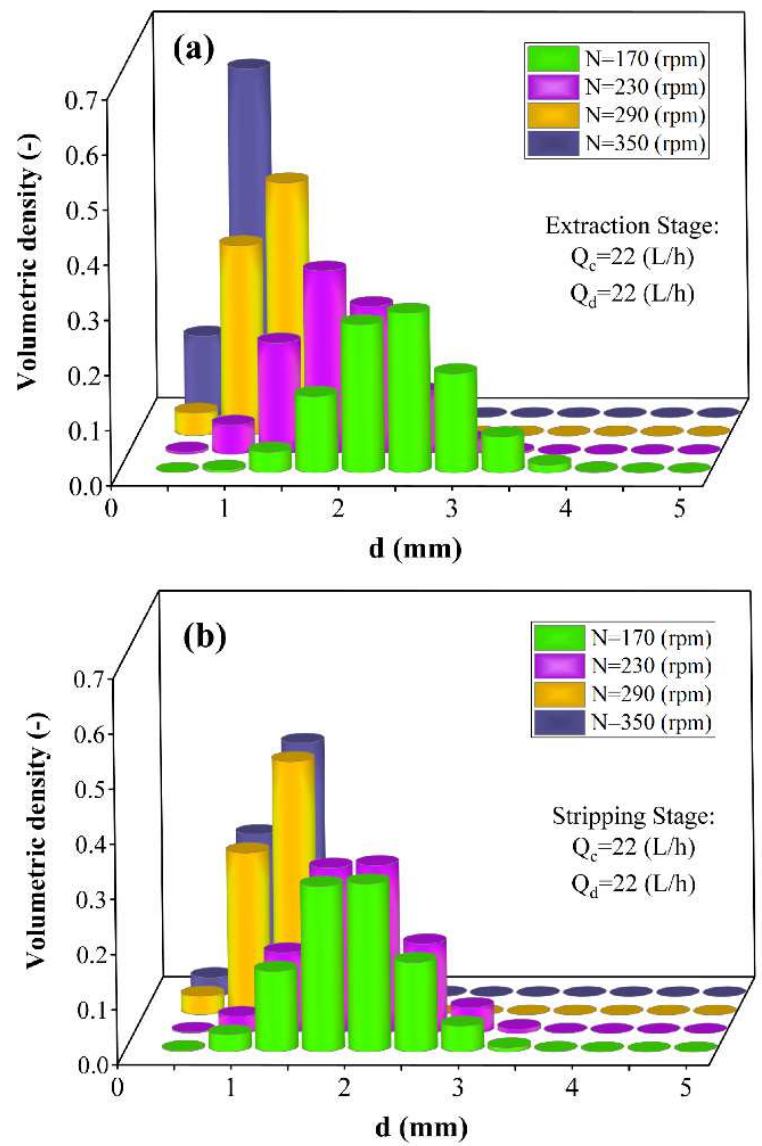

Fig. 5: The effect of rotor speed on volumetric drop size distribution: (a) extraction stage (b) stripping stage 

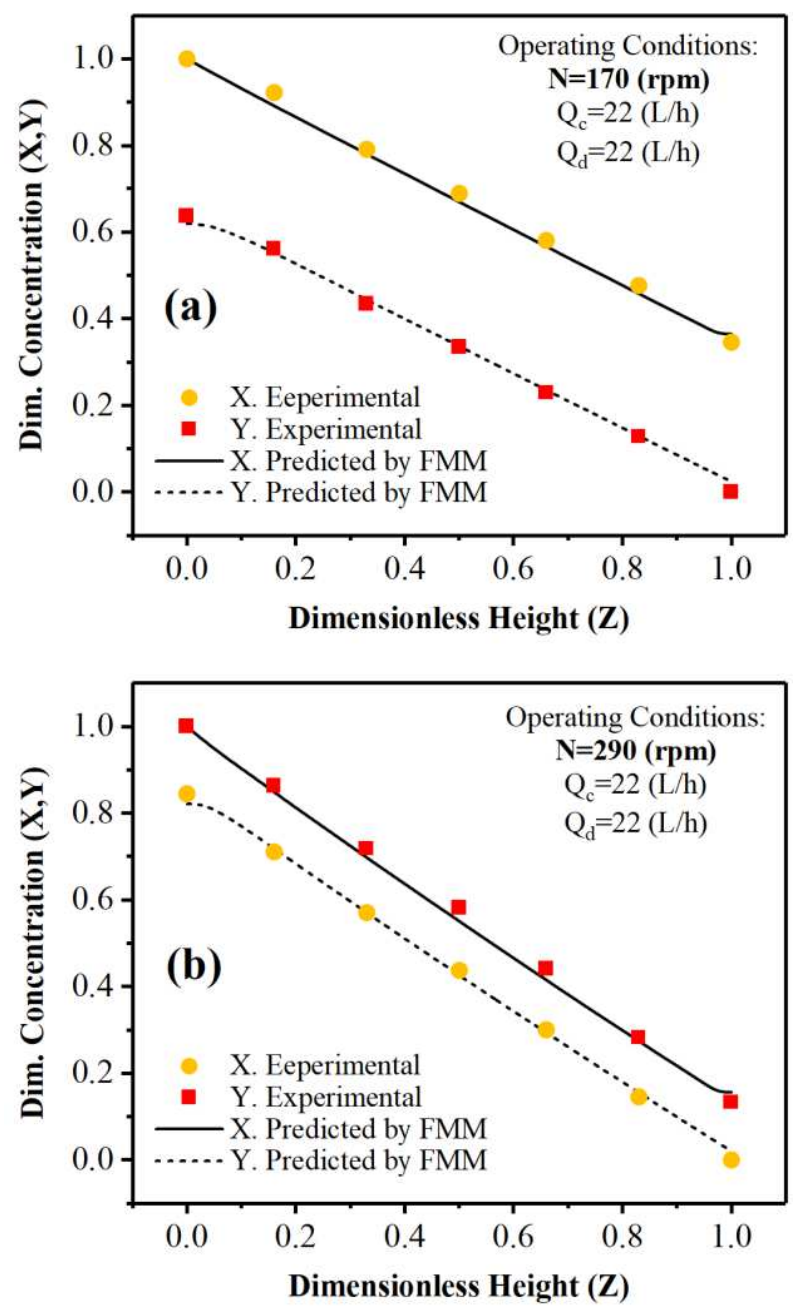

Fig. 6: Comparison of laboratory concentration profiles with predicted by FMM 

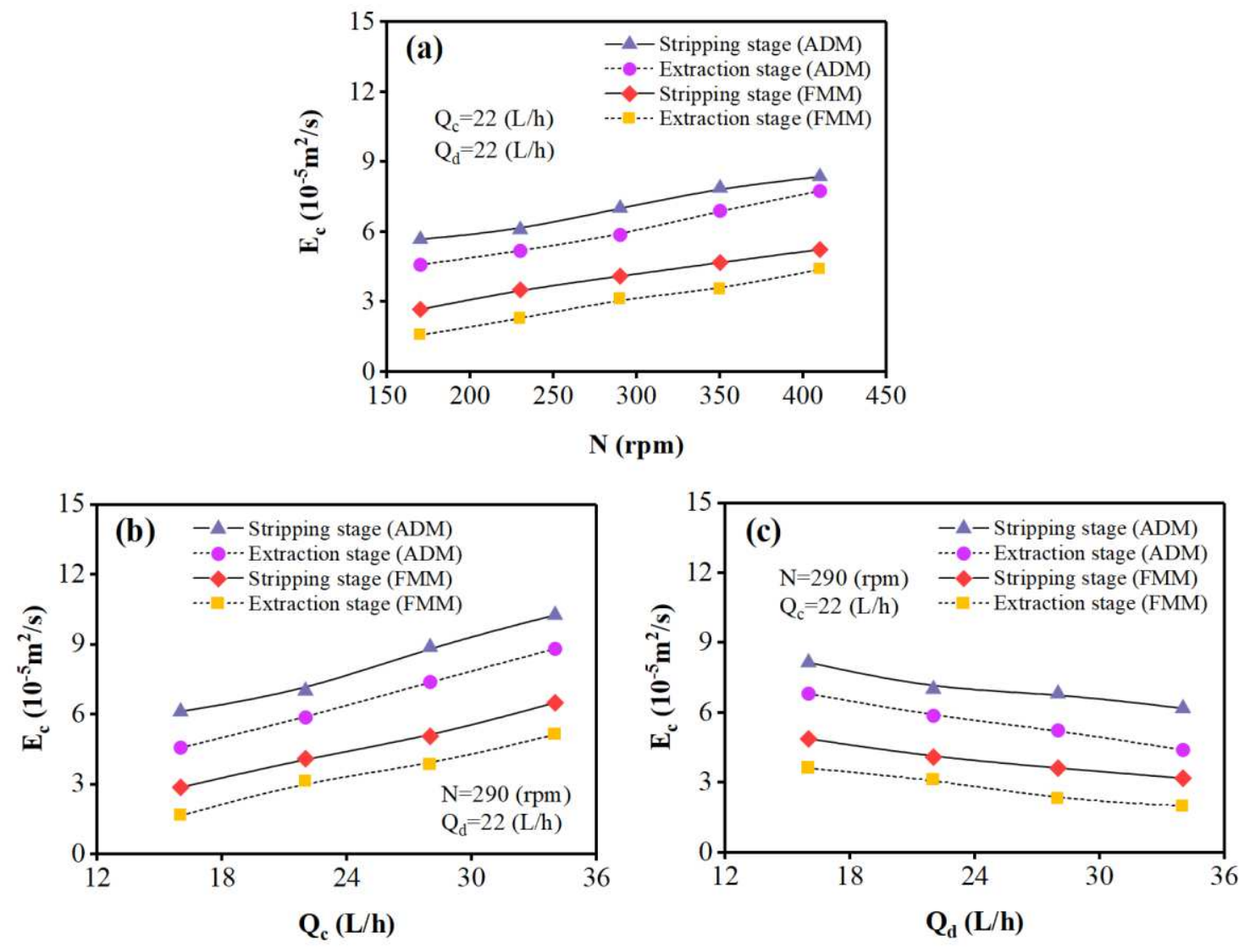

Fig. 7: The effect of operating parameters on continuous phase axial dispersion coefficient obtained by ADM and FMM 

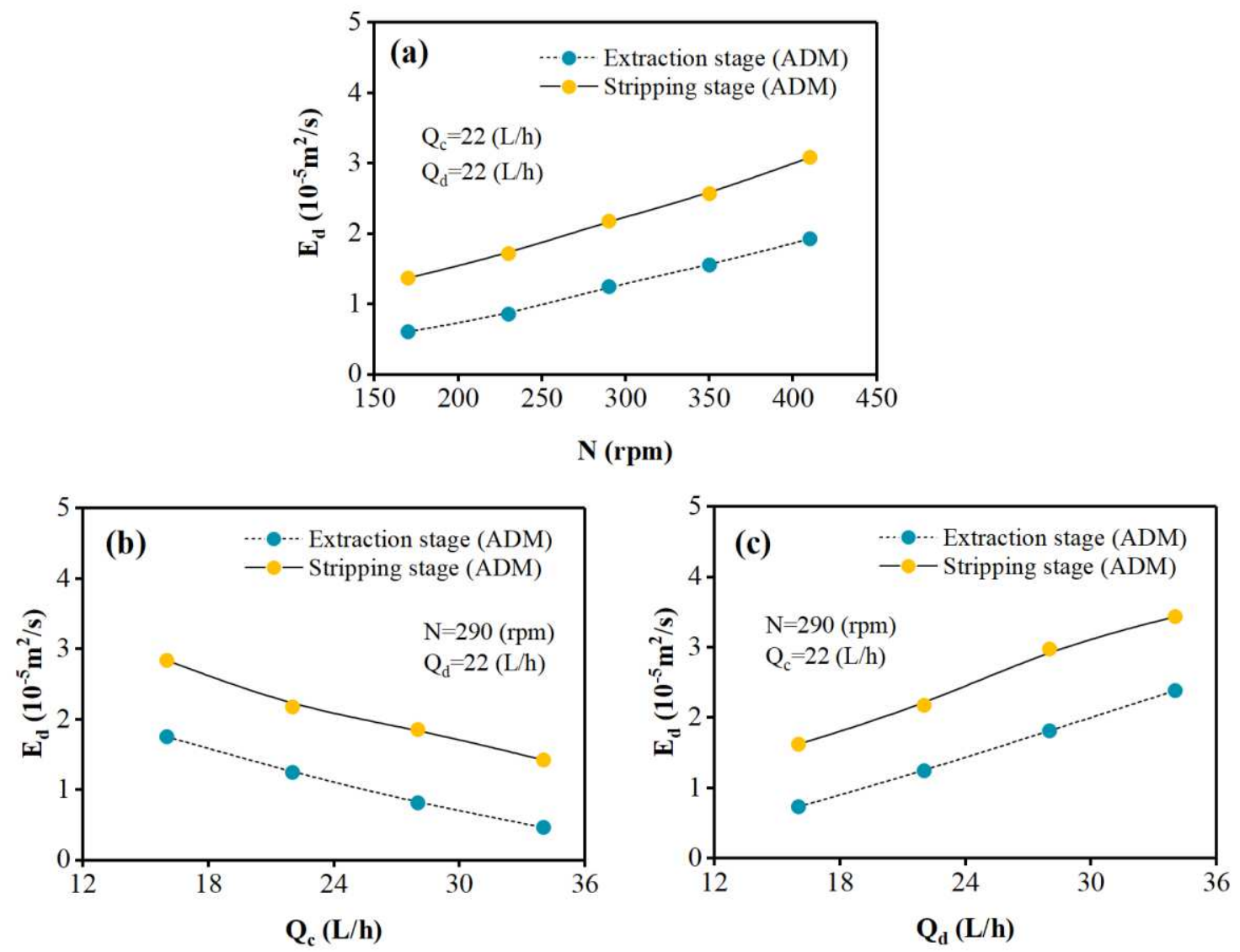

Fig. 8: The effect of operating parameters on dispersed phase axial dispersion coefficient obtained by ADM and FMM 

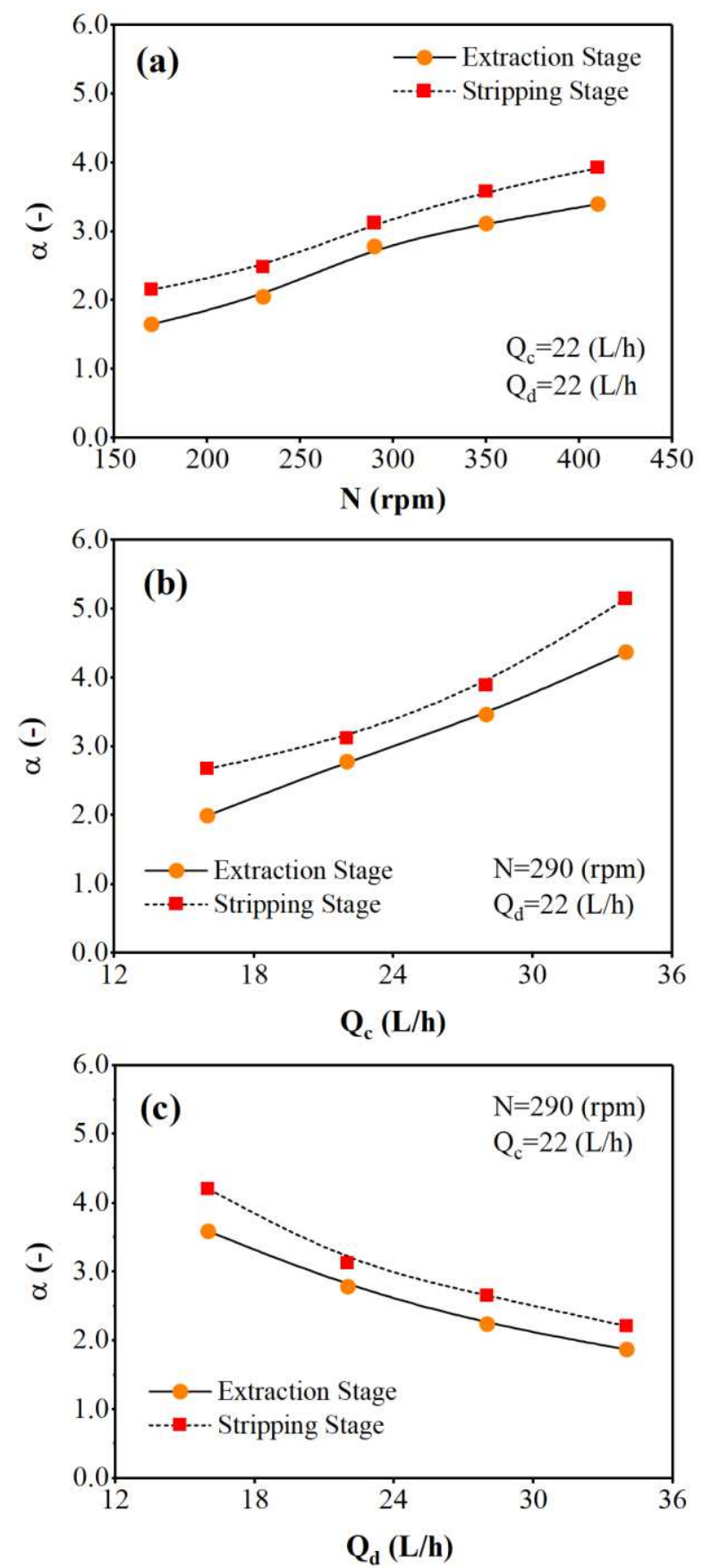

Fig. 9: The effect of operating parameters on continuous phase backflow coefficient obtained by BFM 

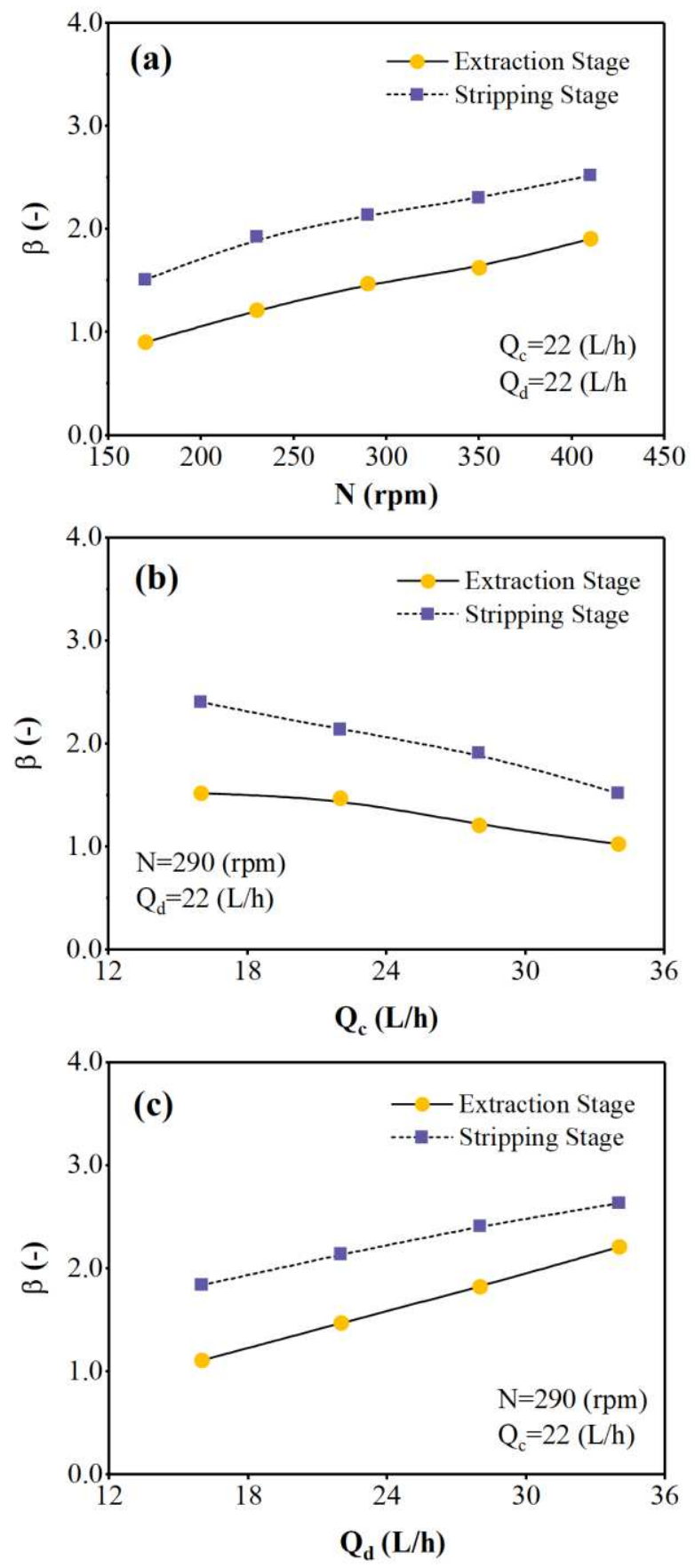

Fig. 10: The effect of operating parameters on dispersed phase backflow coefficient obtained by BFM 

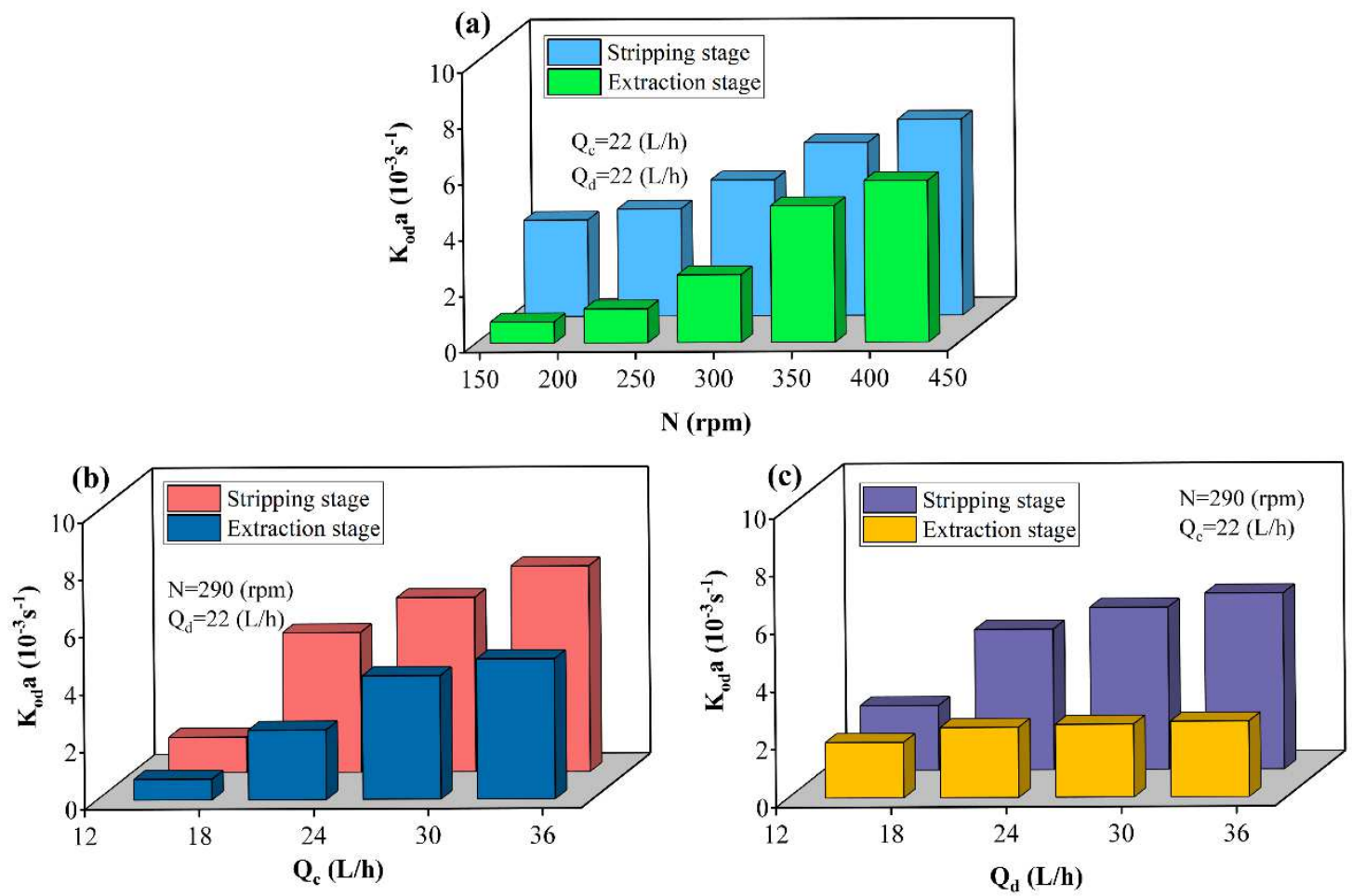

Fig. 11: The effect of operating parameters on volumetric overall mass transfer coefficient obtained by FMM 